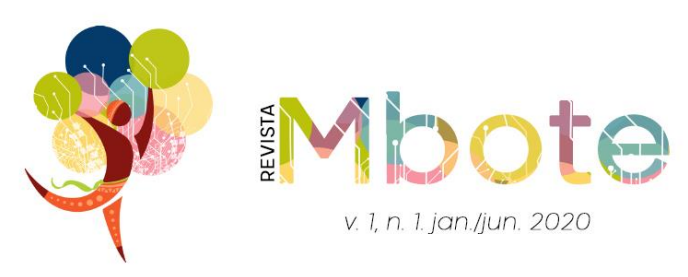

\title{
PESQUISA-AÇÃO, UNIVERSIDADE E SOCIEDADE
}

\author{
Michel Jean Marie THIOLLENT ${ }^{1}$; Maria Madalena COLETTE $^{2}$
}

\begin{abstract}
Resumo: A crescente demanda por pesquisas e conhecimentos adequados para acompanhar as mudanças sociais, intervir em situações comunitárias, ambientais ou organizacionais, e os avanços que a pesquisa-ação vem apresentando na universidade do século XXI incentivam a retomada da fundamentação e do aperfeiçoamento da metodologia de pesquisa-ação, em bases diferentes das do século passado. Ao pensar a gestão da universidade nos pautamos em duas noções centrais: a indissociabilidade entre ensino, pesquisa e extensão; e o papel da instituição na construção de uma sociedade justa e sustentável. Assim, a partir de uma revisão bibliográfica, o presente texto busca refletir sobre o potencial da pesquisa-ação em propiciar as interações necessárias entre conhecimento científico e saberes populares e contribuir com uma reorientação solidária da relação universidade-sociedade. Neste trabalho são abordados os seguintes tópicos: fundamentos da pesquisa-ação; sua situação atual no mundo acadêmico; os temas universidade, sociedade e transformação social; ecologia dos saberes e sustentabilidade; motivação e construção do conhecimento; e pesquisa-ação educacional. Nas conclusões, apresentamos uma agenda de tópicos que podem servir de base a futuros trabalhos e discussões tornando a pesquisa-ação mais atualizada, mais bem conhecida e mais atuante na universidade.
\end{abstract}

Palavras-chave: Pesquisa-ação. Universidade. Ecologia dos Saberes. Comunidades Sustentáveis.

\section{ACTION RESEARCH, UNIVERSITY AND SOCIETY}

Abstract: The increasing demand for research and appropriate knowledge to monitor social changes, intervene in environmental or organizational community situations, and the advances that action research is showing at the university in the twenty-first century encourage the resumption of the grounds and improving the methodology of action research. To think the management of the university, two central notions lead us: the inseparability between teaching, research and extension, and the role of the institution in building a sustainable society. Thus, from a literature review, this paper seeks to reflect on the potential of Action-Research in providing the necessary interactions between scientific knowledge and popular knowledge, and contribute to a solidarity reorientation of the relationship between university and society. The text that follows is developed from the following topics: foundations of action research; its current status in the academic world; the university, society and social transformation issues; "ecology of knowledge" and sustainability; motivation and construction of knowledge; action research and educational foundations of action research. In conclusion, we present an agenda of topics that can be the basis for

\footnotetext{
${ }^{1}$ Doutorado em Sociologia - Université de Paris V (René Descartes) (1975). Formação em Desenvolvimento Econômico e Social - Institut d'Etude du Développement Économique et Social - Université de Paris I (Panthéon-Sorbonne) (1966-1971). Trabalhou como Professor da UNIGRANRIO no PPGA - Programa de Pós-Graduação em Administração (2011-2019). Anteriormente: Professor associado da Universidade Federal do Rio de Janeiro/COPPE (1980-2011). Professor de Sociologia do Instituto de Filosofia e Ciências Humanas da UNICAMP (1975-1980). Tem experiência nas áreas de Estudos Organizacionais; Metodologia de Pesquisa Qualitativa e Participativa; Gestão de Projetos Sociais e Educacionais

${ }^{2}$ Educadora. Graduada em Tecnologia da Construção Civil pela Universidade Estadual Paulista Júlio de Mesquita Filho / UNESP (1980); com Licenciatura Plena, Faculdade Béthencourt da Silva / Sociedade Propagadora das Belas Artes (1985). Mestre em Educação pela Universidade Federal Fluminense / UFF (1992). Doutora em Administração pela Universidade do Grande Rio / UNIGRANRIO (2017).
} 
further work and discussions making the most current action research, most well known and most active in the university.

Keywords: Action Research. University. Ecology of Knowledge. Sustainable Societies.

\section{INTRODUÇÃO}

Ao pensar a gestão da universidade nos pautamos em duas noções centrais: a primeira refere-se à indissociabilidade entre ensino, pesquisa e extensão e a segunda refere-se à inserção da universidade nos processos de construção de sociedades sustentáveis, seu papel face à necessidade de se manter a diversidade ecológica, social e cultural dos povos. Neste sentido, o presente artigo busca contribuir na identificação de caminhos para uma inserção criativa das instituições de ensino superior, voltada à construção de relações horizontais internas - entre os diferentes segmentos da comunidade acadêmica - e com o ambiente externo - os diversos atores presentes nos territórios de sua atuação.

Partimos da perspectiva apontada por Boaventura de Sousa Santos, que coloca a pesquisa-ação como um eixo da universidade no século XXI. Para este autor uma nova centralidade há que ser concedida à pesquisa-ação na universidade, como estratégia de promoção de uma ecologia dos saberes, por seu potencial para propiciar as interações necessárias entre conhecimento científico e saberes populares e contribuir numa reorientação solidária da relação entre universidadesociedade, necessária à restauração da legitimidade da instituição como espaço social de fato. A pesquisa-ação e a ecologia dos saberes são áreas de legitimação da universidade que transcendem a extensão, diz o autor, pois atuam também na pesquisa e na formação (SANTOS, 2008).

Compreende-se que a metodologia da pesquisa-ação e a pesquisa participante podem contribuir para maior articulação entre ensino, pesquisa e extensão, gerando interações entre universidade e sociedade, e contribuindo para uma atualização da universidade, no sentido de um aprofundamento democrático interno e externo à instituição, e de sua contribuição na identificação e na solução de problemas locais, nacionais e globais. Tal perspectiva de atuação, pautada em processos 
participativos, abertura ao meio externo e princípios de sustentabilidade, certamente exige mudanças organizacionais das universidades, assim como das demais organizações da sociedade. Destacam-se as mudanças voltadas à criação de estruturas internas mais flexíveis, mais dinâmicas, capazes de bem lidar com o lado humano da organização e de responder às exigências da realidade contemporânea.

Há uma atualização da pesquisa-ação que era conhecida nas décadas de 70 e 90 em práticas sociais, mas sem grande valor acadêmico. As propostas de pesquisaação e de pesquisa participante contribuíam para alimentar as expectativas de mudança. Por sua vez, o modelo de pesquisa-ação divulgado no pequeno livro introdutório de 1985, sem pretensão, um tanto envelhecido, teve sua $18^{\text {a }}$ edição em 2011, e continua adotado como livro didático em muitos lugares e em diferentes áreas sociais e técnicas (THIOLLENT, 2011). No Brasil as contribuições de Paulo Freire, Carlos Rodrigues Brandão, João Bosco Pinto são importantes e frequentemente referenciadas. Vale lembrar a grande influência da variante "pesquisa participante" no Brasil e na América Latina.

Ao longo dos anos houve momentos de avanço e de recuo na ousadia dos métodos participativos. Perderam fôlego com o neoliberalismo do início dos anos 90, mas voltaram a ganhar espaço com os projetos sociais da época do governo de Fernando Henrique Cardoso e da época do de Lula. Hoje a metodologia participativa é relativamente bem considerada, tanto em certas áreas acadêmicas, quanto em áreas de atuação social e ambiental. Está sendo inserida na concepção de atividades universitárias e inclusive na elaboração de políticas e projetos sociais de maior alcance. É até exigida nas cláusulas de grandes projetos financiados por organismos internacionais.

Objetivando contribuir para o debate sobre a situação atual dessa proposta metodológica na instituição universitária, bem como para a reflexão sobre as potencialidades da pesquisa participante e da pesquisa-ação como elementos de legitimação da universidade como espaço de troca e de construção de saberes e de articulação destes saberes com as necessidades presentes na realidade em que se 
insere, damos aqui os primeiros passos no sentido de uma abordagem panorâmica dos fundamentos da pesquisa-ação a ser ampliada em trabalhos posteriores e de sua situação atual no mundo acadêmico, no Brasil em especial, que ainda oferece resistência aos processos participativos e a uma ecologia dos saberes. Neste sentido, buscamos refletir sobre as vantagens da pesquisa-ação e da pesquisa participante nas relações entre universidade e sociedade, como possível elo articulador entre formação e produção científica e a construção de ações e soluções úteis aos atores e conduzidas com ética.

Enfatizando a necessidade de contribuições continuadas das instituições de ensino superior para a construção de soluções que considerem as características locais, culturais, históricas e ambientais, compreendemos que pela via da participação popular a academia se aproxima da realidade externa e simultaneamente fortalece sua prática institucional no sentido da articulação entre ensino, pesquisa e extensão. Contudo, processos participativos internos serão necessários à efetivação da participação social e à interação de saberes. Situar os sujeitos envolvidos no processo educativo, estudantes e docentes como membros ativos pertencentes a coletividades, organizações e comunidades. Contribuir para que se percebam agentes de investigação, construção de conhecimentos, interações e mudanças pessoais e sociais. Encontrar condições e arranjos de formação para fazer interagir a consciência e o aprendizado socialmente reconhecido.

Estes são alguns pontos que nos parecerem relevantes na reflexão sobre a universidade neste milênio e que abordamos nos tópicos que seguem, como uma primeira contribuição para o debate sobre as possibilidades da pesquisa-ação ou pesquisa participante, como possível eixo articulador da relação universidadesociedade em torno da construção de comunidades sustentáveis.

\section{FUNDAMENTOS DA PESQUISA-AÇÃO}

No plano epistemológico, a pesquisa-ação encontra apoios em várias metateorias: teoria da práxis, teoria crítica, existencialismo (abordagem existencial), 
fenomenologia, pragmatismo, construtivismo social. Estamos denominando metateorias as bases teóricas derivadas de várias filosofias que dão sentido ao uso de métodos e procedimentos em contexto de pesquisa aplicada ou especializada. Embora os atores mais conhecidos optem geralmente por uma ou outra, considerase que a pesquisa-ação, vista em seu conjunto, não se confunde com nenhuma dessas metateorias em particular; pretendemos evitar o fechamento dogmático ou doutrinário. Ademais, diante dos desafios do mundo atual, parece-nos mais importante, no campo das metodologias participativas, buscarmos a convergência ou a complementaridade entre tendências da pesquisa-ação e da pesquisa participante do que a polêmica entre propostas vizinhas, cujas eventuais divergências são secundárias (THIOLLENT, 2011).

Fazer referência a várias filosofias não significa ecletismo, mas tentativa de uma justificada complementaridade entre pontos de vista teóricos e práticos. O importante é dar conta das ações dos atores envolvidos em situações problemáticas, e aprender juntos (pesquisadores e membros das situações) com base nas experiências compartilhadas. Vários pontos de vista são assim comparados, dando lugar à triangulação dos dados e possíveis interpretações dos significados.

Entretanto, essa abertura a vários enfoques têm limites. Por exemplo, há um fato inegável: a pesquisa-ação é incompatível com o estruturalismo ou qualquer outra doutrina (de tipo formalista ou positivista) enfatizando as estruturas em detrimento ao sujeito ou aos atores em situação. Não é por acaso que os autores favoráveis ao estruturalismo, mesmo entre os "progressistas", que declararam a "morte do sujeito", nunca enxergaram a relevância da pesquisa-ação ou de outros métodos participativos. Tais métodos sempre pressupõem a atuação de sujeitos individuais ou coletivos dentro de situações e problemas sociais, mesmo quando se trata de questões aparentemente técnicas.

Nos últimos anos, para fundamentar a pesquisa-ação (e/ou pesquisa participativa) no plano epistemológico, recorre-se também ao quadro de referência denominado construcionismo social, variante do construtivismo voltada para a perspectiva pós- 
moderna, que pressupõe forte interação entre pesquisadores e atores sociais na construção do conhecimento. (ÍÑIGUEZ, 2002; GERGEN, 2001).

Ainda em matéria de fundamentos, é preciso sublinhar a importância da problematização da ação em sua relação com a cognição, já que a pesquisa-ação pretende se diferenciar da pesquisa convencional justamente pelo fato de estabelecer condições proveitosas para a geração de um conhecimento enraizado nas práticas ou em ações de caráter social, educacional, comunicacional, etc. Em filosofia, ao longo da história, existem várias concepções acerca da relação entre o conhecer, o agir ou o fazer. Algumas se referem à teoria da práxis, outras, à fenomenologia, pragmatismo, praxiologia, agir comunicativo, reflexividade (reflexão na ação). Na situação atual, observa-se que a maioria dos praticantes da pesquisaação tem uma visão bastante limitada a respeito dessa questão, que se resolve em geral por uma imprecisa referência à ligação entre teoria e prática ou ao círculo ação-reflexão-ação. Neste ponto, um grande esforço de fundamentação ainda é necessário para superar as limitações vigentes e, talvez, descobrir novas possibilidades de articulação.

Complementarmente à problemática da ação, encontra-se também a do ator ou sujeito, individual ou coletivo. Na pesquisa-ação, os atores estão no centro das atenções, quer como indivíduos ou grupos ativos dentro da situação investigada, quer como pesquisadores, parceiros ou demais participantes no processo. Em cada campo de investigação os vários tipos de atores devem ser concretamente definidos.

\section{A SITUAÇÃO ATUAL DA PESQUISA-AÇÃO NO MUNDO ACADÊMICO}

No Brasil, ao longo da última década, observou-se que a pesquisa-ação é praticada em maior escala, tanto em projetos de pesquisa - dissertações e teses - como de extensão, e em áreas sociais e técnicas cada vez mais diversificadas. As áreas mais frequentes continuam as de educação e saúde, mas adota-se também o método de pesquisa-ação em áreas vistas como mais técnicas, como engenharia de produção, ergonomia, informática, agronomia, agroecologia, etc. 
A despeito dessa tendência otimista, ainda permanecem certas dúvidas quanto à cientificidade da pesquisa-ação e sua viabilidade acadêmica. Os partidários de métodos convencionais, sobretudo de tipo quantitativo, veem com maus olhos os projetos de pesquisa-ação, com a participação dos atores que seria um fator de perda de objetividade científica. Embora a questão seja complexa e mereça longa discussão, considera-se que a pesquisa-ação possa ser conduzida com rigor observacional e controle de distorções. Deixou de ser vista como prática apenas militante e passou a ser concebida e aplicada em contextos mais profissionais e institucionais. Ademais, com a atual revalorização acadêmica dos métodos de pesquisa qualitativa, amplas considerações epistemológicas relativas a esse tipo de pesquisa também se aplicam à pesquisa-ação, muitas vezes, concebida como tipo de pesquisa qualitativa. Seja como for, é importante empenhar-se em um vasto esforço de renovação e consolidação da metodologia da pesquisa-ação e de suas modalidades participativas para legitimar seu uso e aumentar sua viabilidade em universidades e centros de pesquisa científica.

Diante da crescente demanda em matéria de pesquisas e de conhecimentos adequados para acompanhar mudanças sociais, definir projetos, programas ou políticas públicas, intervir em situações comunitárias, ambientais ou organizacionais, a metodologia de pesquisa-ação está adquirindo nova atualidade. Entretanto sua divulgação é bastante limitada. Ainda faz falta na capacitação de muitos estudantes e pesquisadores.

Na parte técnica, hoje fica cada vez mais viável a construção de novos dispositivos de pesquisa e de planejamento recorrendo às tecnologias de informação e comunicação. Até os dados verbais e visuais podem ser objeto de processamento informatizado. Mas, para que isso ocorra, a capacitação dos técnicos e pesquisadores é pré-requisito. Graças a esses recursos técnicos, grandes projetos são viabilizados com a participação de grupos, arranjos institucionais e redes de cooperação. 
Outro problema crucial é de natureza diferente. A pesquisa-ação requer a participação das partes interessadas, sem a qual a proposta perde sua substância e vira procedimento convencional. Muitos projetos de pesquisa ordinária são repetitivos, sem perspectiva de mudança efetiva e acabam desvalorizando a pesquisa social em vários públicos. É preciso encontrar meios apropriados para aumentar a credibilidade dos projetos junto às populações, assegurando a continuidade, sem criar expectativas insustentáveis, e mostrando resultados reais, mesmo que parciais. Além disso, a difusão dos resultados é fundamental para que os membros da população ou os grupos de atores constituídos possam utilizá-la em suas ações.

A divulgação de resultados específicos da pesquisa-ação continua bastante limitada no meio acadêmico. Faltam revistas dedicadas a esse tipo de proposta metodológica. Além disso, as publicações oriundas da extensão universitária são pouco valorizadas e circulam com grandes dificuldades. As equipes deveriam se preocupar em produzir e publicar maior quantidade de conhecimentos baseados na pesquisa-ação em diversos canais, inclusive em veículos digitais e audiovisuais. Para os docentes e pesquisadores, é desejável que obtenham maior reconhecimento acadêmico através de publicações em periódicos indexados em diferentes áreas de ciências sociais, educação, administração, etc.

O principal argumento acerca do futuro da pesquisa-ação na Universidade do século $\mathrm{XXI}$, que significa também o maior desafio, foi apresentado por Boaventura de Sousa Santos (2008). Após o choque neoliberal dos anos 1990, diante da crise com perda de identidade e legitimidade das universidades públicas e privadas submetidas aos imperativos do mercado, o autor mostra que uma possível reforma democrática e emancipatória, entre outras medidas, passa pelo fortalecimento da extensão, da pesquisa-ação e da ecologia dos saberes, ampliando o entrosamento da universidade com a sociedade de modo contra hegemônico. Esse ponto de vista, voltado para o futuro, apoiado em muitas experiências em curso no Brasil e em outros países, constitui incentivo para a retomada da fundamentação e do 
aperfeiçoamento da metodologia de pesquisa-ação, em bases diferentes das do século passado.

\section{PESQUISA-AÇÃO NA RELAÇÃO UNIVERSIDADE E SOCIEDADE}

O desafio para a universidade é obter resultados, de um lado, no quadro de formação e produção científica e, por outro lado, voltados para ações e soluções adequadas ao contexto, úteis aos atores e conduzidas com ética. Resultados de uma universidade que sai do isolamento social, se desvencilha do "inimigo interno", suas armadilhas burocráticas e seus "interesses corporativos socialmente injustos", integrada à sociedade não pela estreita via do mercado, mas assumindo sua responsabilidade social pela via do "conhecimento pluriversitário" solidário, como proposto por Boaventura de Souza Santos (2008).

A pesquisa-ação pode constituir um caminho real de articulação entre ensino, pesquisa e extensão, gerador de interações entre universidade e sociedade, e contribuir para uma atualização no sentido de um aprofundamento democrático interno e externo à instituição. A educação superior deverá responder às demandas por democratização incluindo não só as pessoas, também seus saberes tradicionalmente excluídos da universidade. Alternativas de pesquisa, de formação, de extensão e de organização da universidade como bem público, deverão ser promovidas de forma que em sua especificidade esta contribua na identificação e na solução de problemas locais, nacionais e globais (SANTOS 2008).

Referindo-se a uma busca por legitimidade, Boaventura ressalta, entre outros pontos, que a universidade do século $X X I$ deve se pautar na pesquisa-ação como articulação dos interesses sociais e dos interesses de pesquisa, para além das demandas de mercado, numa atuação que integre ensino, pesquisa e extensão, para definição e elaboração dos projetos de pesquisa, envolvendo a participação da comunidade e seu beneficiamento com os resultados da pesquisa. Ou seja, atuar em direção a uma "ecologia dos saberes", segundo ele, "uma forma de extensão ao contrário", de fora para dentro da universidade, que trata do diálogo entre saber 
popular e conhecimento científico, da percepção da validade de outros conhecimentos, de se reverter uma "injustiça cognitiva" que está no âmago da injustiça social, contribuindo para a desqualificação dos saberes locais e para a marginalização social dos grupos que destes dispõem (SANTOS 2008).

A ecologia do saber e a pesquisa-ação são vistas por este autor como estratégias de reorientação solidária da relação universidade-sociedade. Promovem o diálogo entre diferentes modos de conhecimento, convertendo a universidade em espaço público de fato, “... de interconhecimento onde os grupos sociais podem intervir sem ser exclusivamente na posição de aprendizes..." em prol de benefícios mútuos. Trata da valorização de conhecimentos científicos e não científicos, cuja “... partilha por pesquisadores, estudantes e grupos de cidadãos possibilita a criação de comunidades epistêmicas mais amplas." (SANTOS 2008).

A pesquisa-ação é instrumento de diálogo e de construção de novas práticas acadêmicas, de práticas que pressupõem a concepção de universidade como espaço social, voltado à construção de conhecimentos que possam alavancar transformações em prol da sociedade como um todo, quer no campo social, ambiental, econômico, tecnológico, científico, educacional e cultural.

\section{UNIVERSIDADE E TRANSFORMAÇÃO SOCIAL}

O papel das instituições de ensino superior na construção do bem estar social e de uma sustentabilidade tem sido objeto de estudos em administração. Milano \& Goulart (2003) abordam questionamentos surgidos a cerca do papel das instituições de ensino superior, visto que "seu produto e objeto - o conhecimento - é elevado à categoria central" no contexto da chamada "sociedade do conhecimento". Aos autores "a intervenção das universidades deve se dar por meio de sua missão formadora de mentalidade e renovadora de conceitos e não como uma usina de proposições e formatos acabados e definitivos de políticas públicas (MILANO \& GOULART, 2003)". Ponto de vista que coloca a universidade como uma dentre as 
organizações da sociedade que devem integrar a rede de atores do desenvolvimento local.

Na era das redes de informação e conhecimento a "formação de mentalidade" e a "renovação de conceitos" ganha outros terrenos. As novas tecnologias aceleram a transmissão de conteúdos, estimulando interatividade, criatividade, pensamento divergente, criticidade. O conhecimento se constrói por vias diversas em processos cooperativos e autônomos. A universidade cada vez mais deve constituir-se como organização aberta ao meio externo, no sentido de contribuir com o desenvolvimento da sociedade e de comunidades e, concomitantemente, de receber as contribuições dos demais atores sociais. $E$ tal contribuição necessita fazer-se, não apenas com a "comunidade industrial", mas, de forma abrangente e permanente com as demais organizações que atuam no território, para a construção conjunta de novos conhecimentos e de novas realidades mais sustentáveis.

A efetivação de contribuições continuadas das instituições de ensino superior para a construção de soluções a partir das condições e características locais, culturais, históricas e do ambiente natural, como estratégia de aproximação da vida acadêmica à realidade externa, poderá contribuir para elevar o nível dos profissionais formados e fortalecer a prática institucional no sentido da articulação entre ensino, pesquisa e extensão.

Cooperação, relações horizontais e aprendizado contínuo são dinâmicas inerentes à criação de um ambiente sinergético para se enfrentar os problemas colocados, identificar o potencial local, os recursos endógenos e as soluções adequadas, com base no princípio da complementaridade, na percepção das relações de interdependência. Processo que precisa ser calçado por novas informações, pela construção interativa de novos conhecimentos e pela definição e concretização de ações condensadas.

O processo de formação acadêmica pode e deve contribuir para a geração de inovações articuladas às necessidades e às potencialidades comunitárias, locais e 
regionais. A adoção de metodologias e processos participativos nas três esferas de atuação da educação superior pode refletir e ser refletida em relacionamentos da comunidade acadêmica com a comunidade externa. Os métodos participativos de pesquisa promovem cooperação, intercâmbio e reforçam o aprendizado como processo contínuo, pois reconhecem que o conhecimento se constrói em rede, acolhendo as diferentes contribuições presentes no território.

Em qualquer tempo e, especialmente, na atual "sociedade do conhecimento" a educação deve corresponder à aprendizagem para a mudança, o que significa dizer aprendizagem para 0 enfrentamento das mudanças aceleradas que 0 desenvolvimento tecnológico impulsiona hoje e, também, para a mudança como permanente movimento transformador do mundo, como busca de melhores condições de vida.

$\mathrm{Na}$ visão de Paulo Freire (1981) a educação para se enfrentar o processo de mudança promove a formação da uma consciência crítica, instrumento maior para a efetivação de transformações significativas, tanto no plano individual quanto no plano global da sociedade. Ele nos diz que processos educacionais- no ensino, na pesquisa e na extensão - precisam contemplar três dimensões da aprendizagem: a dimensão cognitiva - aprendizagem de novos conteúdos e informações; a dimensão das habilidades - desenvolvimento de competências práticas; e a dimensão das atitudes - comportamentos fundamentais à aplicação de conhecimentos transmitidos e habilidades desenvolvidas e aos relacionamentos daí decorrentes.

Desenvolver tais dimensões e competências implica, necessariamente, situá-las face à realidade em que estão inseridos os sujeitos envolvidos no processo educativo, contribuir para que estes se percebam como objetos e sujeitos de mudança e para que os mesmos venham situar sua atuação profissional como atuação na sociedade, o que pressupõe a integração do próprio desenvolvimento e sustento a uma contribuição para com o desenvolvimento da sociedade. 
Adotar o caminho da pesquisa-ação, da pesquisa participante, significa adotar o diálogo, “... o encontro amoroso (ou sensível) dos homens que, mediatizados pelo mundo, o pronunciam, isto é, o transformam, e, transformando-o, o humanizam para a humanização de todos." Possibilitar tal dialogicidade implica levar em conta os referenciais históricos e culturais das partes envolvidas. Conforme Bosco Pinto (1986), a pesquisa-ação como prática pedagógica busca integrar o potencial de conhecimento e criatividade da cultura popular com conhecimento científico (teorias, conceitos, métodos e tecnologias). Possibilita mais que uma troca, supõe a confrontação entre estes saberes e a sua superação num saber novo de caráter transformador, numa prática política cuja estratégia central é a participação na produção de conhecimentos, na organização e articulação de grupos, na ação coletiva, conscientemente concertada.

O "diálogo problematizador", entre as várias razões que o fazem indispensável, diminui a distância entre a "expressão significativa" do pesquisador e a percepção pelo grupo pesquisado em torno do "significado", que passa a ter a mesma "significação" para ambos (FREIRE, 2011). À universidade do século XXI cabe possibilitar tal diálogo nas esferas do ensino, da pesquisa e da chamada extensão, com seus pares, seu público interno e com a rede de atores externos, diálogo pautado pela realidade em que se inserem.

\section{ECOLOGIA DE SABERES E SUSTENTABILIDADE}

Nesta perspectiva participativa, a própria instituição pesquisadora consiste em objeto de pesquisa, tanto quanto o grupo externo pesquisado. O grupo de "pesquisadores" - membros da comunidade acadêmica - ao se envolver na pesquisa, em sua elaboração e aplicação, também será envolvido na ação presente no território e "objeto" da pesquisa. O grupo de "pesquisados", atores que integram uma situaçãoproblema, ao analisar e refletir sobre sua realidade de forma participativa estará também pesquisando e elaborando questões presentes no contexto. Trata-se de um processo em que diferentes saberes são considerados, possibilitando a articulação de rede(s) interna(s) à universidade relacionada(s) às temáticas em estudo, pela 
interdisciplinaridade e pelo envolvimento de diferentes segmentos e atores presentes na organização, a contribuir para uma "ecologia humana" e uma "ecologia dos saberes" em seu ambiente interno e no ambiente externo.

Uma ecologia das relações humanas, entre os homens e entre estes o seu meio, capaz de promover uma "sociedade sustentável" baseada na convivência e na colaboração com a diversidade social e cultural para a manutenção da diversidade ecológica, deve orientar a atuação das instituições de educação superior. Indo de encontro à necessária reversão da "injustiça cognitiva" que, esclarece Boaventura, também se manifesta na escala global, onde os países periféricos ricos em saberes não científicos, destituídos de valor e até dizimados em nome de um conhecimento científico considerado como único válido, sofrem os impactos negativos ambientais, sociais e culturais do desenvolvimento científico (SANTOS 2008).

O conceito de sociedade sustentável é contraposto por Diegues (1992) à noção de desenvolvimento sustentável, que segundo o autor se pauta na concepção de que o desenvolvimento deve estar referenciado nos insustentáveis padrões atingidos pelas sociedades industrializadas. Ele relaciona a ideia de sociedade sustentável à “... noção expressa por Chambers na qual as pessoas, sobretudo as mais pobres, devem ser sujeitos e não objetos de desenvolvimento", diz que não existe uma única definição de sistema sustentável e que para existir uma sociedade sustentável é necessária a sustentabilidade ambiental, social, cultural e política, como um processo e não como um estágio final, pois, ao mesmo tempo, não se propõe um determinado sistema sociopolítico que dure para sempre, mas que deva ter capacidade para se transformar (DIEGUES, 2003).

A questão de fundo que ainda permanece válida para Diegues (2003) é como construir sociedades ecológicas e socialmente mais justas? Em tese a resposta pode ser relacionada à citação de Robert Chambers por Diegues, que vincula o conceito de sociedades sustentáveis à consideração das pessoas como sujeitos do desenvolvimento. Ou seja, os autores apontam para a questão da participação como fator constituinte da noção de "sociedade sustentável" e, consequentemente, da 
sustentabilidade ambiental, social, cultural e política. A participação ativa das pessoas é fundamental ao processo permanente de construção da sustentabilidade, quer como cidadãos de uma comunidade; como indivíduos com necessidades particulares, direitos e deveres; pessoas com capacidades, saberes e motivações; como membros de organizações; como profissionais, intelectuais, estudantes; como empreendedores ou consumidores.

O tema da participação também é comumente relacionado à conceituação e às práticas do chamado desenvolvimento sustentável. Mas, como vimos, neste caso a participação volta-se para o alcance dos padrões de desenvolvimento atingidos pelas sociedades industrializadas, portanto, uma participação subordinada a estilos de produção e consumo não necessariamente vinculados à cultura, à história e ao ambiente social e natural dos participantes.

Então, o que parece relevante em termos das práticas participativas para a construção de sociedades e comunidades sustentáveis, corresponde à vinculação destas práticas aos efetivos interesses, necessidades e potencialidades dos participantes e aos recursos ambientais, culturais, políticos, sociais, econômicos e naturais de que dispõem. Uma "ecologia dos saberes" rumo a uma sustentabilidade própria, agregando à perspectiva participativa um enfoque extremamente qualitativo, que na universidade deve contrapor-se àquela espécie de pesquisa-ação que, Santos (2008) analisou, já acontece e reforça as atividades de extensão em função da globalização neoliberal, em favor de uma pesquisa-ação a serviço do conjunto da sociedade e que integre ensino, pesquisa e extensão.

\section{MOTIVAÇÃO E CONSTRUÇÃO PERMANENTE DO CONHECIMENTO}

A conceituação de "comunidades sustentáveis" destaca a noção de sustentabilidade como processo de busca de equilíbrio entre diferentes fatores, numa realidade em constante transformação, sem um ponto final, como uma qualidade necessária ao viver e à interação com o meio ambiente natural e cultural. E a conjugação destes fatores - diversidade, participação qualitativa e sustentabilidade - como processo 
pode orientar as sociedades e comunidades para uma dimensão ética do desenvolvimento como transformação das relações econômicas, sociais e com a natureza.

Uma participação qualitativa com vistas a tal sustentabilidade requer um processo mais que participativo, implica uma participação interativa, criativa, cooperativa, numa realidade em movimento, cujas partes envolvidas voltam-se continuamente para a construção coletiva do bem estar social e da natureza que suporta a sociedade. Trata-se, pois, de uma conquista para a qual as partes envolvidas devem estar motivadas e ideologicamente identificadas com a transformação da realidade. Um processo de envolvimento mútuo, em termos práticos e teóricos, em que os pontos de vista da comunidade, das pessoas participantes, dos especialistas e das demais partes envolvidas são igualmente discutíveis.

Às comunidades sustentáveis, ancoradas em modos particulares, históricos e culturais de relações com o ecossistema e dos seres humanos entre si, pela afirmação da diversidade, da participação qualitativa e da sustentabilidade como processo, são imprescindíveis organizações abertas, como a universidade do século XXI proposta por Boaventura (2008), capazes de aprender e adaptar-se a novas circunstâncias, abarcando a criatividade de seus colaboradores e colocando-se aberta para a troca criativa com o meio externo, como indica a pesquisa-ação. A participação na geração de bem-estar social, no desenvolvimento da comunidade e na manutenção da capacidade de renovação dos recursos naturais possibilita a uma organização situar-se como "ator social" que articula criativamente seus objetivos específicos aos anseios e necessidades mais amplas da sociedade e, consequentemente, desenvolve sua capacidade de absorver mudanças, de transformar-se e de seguir como organização forte seja qual for sua atividade.

A participação da universidade como instituição com contribuições a oferecer e a receber no processo cooperativo de construção de "sociedades sustentáveis", na perspectiva da ecologia dos saberes e da pesquisa-ação, é muito mais exigente que a simples colaboração, requerer maior comprometimento e reciprocidade entre os 
atores implicados (THIOLLENT, 2009) e deve ser estruturada e dinamizada em função das condições e circunstâncias que caracterizam o meio em que ela opera.

A pesquisa-ação favorece o aumento do conhecimento de todas as pessoas envolvidas no processo e a criatividade coletiva. Reflete a perspectiva freireana que busca reverter tendência a uma "educação bancária" ainda presente na universidade, levando o indivíduo - pesquisador, professor, estudante ou ator local a reconhecer que, coletivamente, no encontro com o outro, pode chegar a gerar um conhecimento crítico da realidade; que através da sua ação pode ser sujeito de sua história; e que através da contribuição do outro pode mudar a si mesmo, contribuir para a mudança do outro e da realidade que os cerca.

O caminho do ensino articulado à pesquisa e à ação possibilita o conhecimento e a análise das realidades, relacionadas ao ambiente interno e ao ambiente externo à Universidade, pelo envolvimento das pessoas - membros da comunidade acadêmica e atores presentes na realidade estudada - implicadas na organização e na aplicação da pesquisa; na consequente criação de uma rede interna voltada ao campo da ação; e na ação e sua sistematização, favorecendo a aprendizagem e apropriação de novos conhecimentos e instrumentos por todos.

Importante considerar, ainda, que para uma prática efetivamente pautada na participação das pessoas implicadas na pesquisa, o grupo de pesquisadores deverá ter incorporado um grau de "identificação ideológica" com os pesquisados, o que não significa considerar que a comunidade sempre esteja certa, há que se ter um distanciamento que possibilite a crítica, a autocrítica e horizontes alternativos. Tal ponto de vista deverá ser tomado como um princípio a nortear o desenvolvimento da pesquisa em todas as suas esferas, com vistas a um processo criativo e transformador de todos os que nele se envolverem. Pois, como diz Paulo Freire, a estrutura que se transforma não é sujeito de sua transformação, no desenvolvimento o ponto de decisão se encontra no ser que se transforma (FREIRE, 2011). 


\section{PESQUISA-AÇÃO EDUCACIONAL}

Além de serem métodos de pesquisa, com capacidade de observação a ser acoplada à ação, a pesquisa-ação e a pesquisa participante oferecem também subsídios para projetos e práticas que não se limitam à pesquisa stricto sensu, mas abrangem procedimento de ensino, de planejamento de atividades, de avaliação de programas sociais, etc.

Existe uma longa tradição de pesquisa-ação educacional de origem inglesa (ELLIOTT, 1990, 1993), baseada nas experiências de Stenhouse ou Elliott, que se aplica na prática pedagógica, em ambientes escolares de vários níveis. Em vez de serem meros repassadores de conteúdos preestabelecidos pelas diretrizes do sistema de ensino e da pedagogia convencional, com a pesquisa-ação os docentes desempenham um papel ativo como pesquisadores, adequando o conteúdo do ensino às expectativas e ao contexto de vida dos alunos. De acordo com esta visão, o professor investiga junto com os alunos, ampliando os horizontes de conhecimento, estimulando o desempenho e a criatividade dos mesmos. $\mathrm{Na}$ pesquisa-ação educacional, além dos professores, os alunos também adquirem uma atitude investigativa. Para além da sala de aula, eles são incentivados a aprender com base em suas próprias pesquisas orientadas pelos professores, a respeito de problemas observáveis no entorno social, geográfico, ambiental, na cidade, no campo ou na natureza.

Também deve ser considerada a concepção de pesquisa-ação de grande influência no plano internacional, que se concentra em torno na formação de professores com intuito de fazer prevalecer na educação valores de democracia, justiça social, luta contra discriminações, etc. (KEMMIS, WILKINSON, 2011; DINIZ-PEREIRA, ZEICHNER, 2011).

Para integrar as várias áreas de conhecimento relativas às práticas vigentes e às ações e mudanças a serem delineadas e implementadas com a participação dos interessados, é preciso superar as limitações do pensamento analítico, que isola 
cada aspecto ou elemento da realidade, e adotar uma visão sistêmica, que apreende a complexidade do que está sendo considerado como realidade. Não existe unanimidade quanto às características dessa visão. Entre as mais difundidas, existem várias abordagens, como a antiga teoria geral dos sistemas de Ludwig von Bertalanffy, a teoria da complexidade de Edgar Morin, as teorias de Francisco Varela e Humberto Maturana, a contribuição de Peter Checkland e a de Jean-Louis Le Moigne, apoiada no construtivismo. Sem dúvida, tais abordagens de sistemas e complexidade têm encontrado dificuldades na divisão por disciplinas do trabalho acadêmico convencional, o que tem contribuído amplamente para o surgimento e o crescimento da interdisciplinaridade, em particular, quando se trata de conectar o social e o natural ou ambiental (GARCíA, 1994).

A repercussão dessas abordagens sistêmicas na metodologia de pesquisa-ação não foi imediata, pois são concepções bastante abstratas, e algumas delas têm sido criticadas por suspeita de reabilitar certo tipo de organicismo ou de funcionalismo. Todavia, recentemente, encontram-se bastante consolidadas em autores como André Morin $(2004,2010)$ e El Andaloussi (2004), que desenvolveram uma concepção da educação de adultos e formação permanente baseada nos procedimentos de pesquisa-ação. Os projetos de pesquisa-ação vinculados à formação são conduzidos de modo individual ou em grupos, em torno de problemas julgados relevantes no plano social e no plano individual, levando em conta a biografia dos autores e atores.

Conforme essa concepção, a formação pretendida deve aliar consciência social e capacitação técnica aproveitável pelas pessoas em seus contextos de atuação. Não se trata de reduzir a formação permanente a um tipo de treinamento/ aperfeiçoamento profissional, mas é preciso encontrar condições e arranjos de formação para fazer interagir a consciência e o aprendizado técnico socialmente reconhecido, seja de tipo remunerado, seja de tipo voluntário. A questão do reconhecimento aparece sempre como condição de viabilidade e de continuidade da formação. 
Diferente da ênfase que é frequentemente dada às técnicas de educação à distância, mas sem negar sua utilidade, a aproximação entre educação permanente, extensão universitária e pesquisa-ação dá privilégio a situações presenciais, participativas, cooperativas, com diálogo entre pessoas reais. A tecnologia é vista apenas como meio complementar para a ação educacional.

Ao educando é preciso uma profunda reflexão sobre si próprio (autobiografia), sobre seu entorno e sobre as práticas sociais nas quais ele está engajado. Nesse contexto, a pesquisa-ação é vista como estratégia de auto-formação. Estudantes e docentes atuam como membros ativos pertencentes a coletividades, instituições ou comunidades rurais ou urbanas, implicados em práticas sociais relacionadas com associações, cooperativas, sindicatos, grupos políticos ou de expressão cultural, dentre outros.

Embora possa ser aplicada em qualquer área de conhecimento relacionado com uma atividade onde houver interação entre seres humanos, ou entre seres humanos e seu ambiente, a pesquisa-ação encontra na educação uma vocação particular. Embora seja comum vincular a pesquisa-ação à educação de adultos e à formação permanente, a educação formal de níveis médio, fundamental ou superior, também pode ser objeto de pesquisa-ação.

Com a pesquisa-ação, o docente desempenha um papel de pesquisador sobre: o conteúdo do ensino; a didática; a melhoria da aprendizagem dos alunos, os valores da educação. O professor-pesquisador tem autonomia. Seu ensino está embasado em pesquisa e não em conhecimentos prontos, codificados em material de instrução. Professores e alunos não são consumidores de conhecimento, são produtores dialogando por meio da pesquisa, com cooperação ou colaboração, a seu alcance, por meio de observações, leitura e reflexão.

Isso requer uma forte implicação (ou motivação) por parte dos professores, com carga horária de ensino reduzida para possibilitar o trabalho de pesquisa. Tornar pesquisador o docente em suas atividades cotidianas requer uma série de condições 
sociais e institucionais que nem sempre existem na prática. Daí a dificuldade de uma difusão dessa metodologia em grande escala.

Deve-se a Boaventura de Sousa Santos (2010) uma profunda elaboração do papel da pesquisa-ação no contexto das universidades do século XXI. A referida metodologia é vista como geradora de projetos e situada na interface entre docência, a pesquisa e a extensão universitária. Ela dá suporte a uma "ecologia dos saberes", proporcionando a troca entre conhecimentos científicos e saberes sociais ou culturais. Tal proposta se apresenta como condição a ser incentivada para promover a democratização e a emancipação através das práticas universitárias.

O bom sinal é que Já existem exemplos de experiências desse tipo em universidades na América Latina e no Brasil, em particular em campi avançados, ou em políticas de interiorização, onde há de projetos de integração de atividades da universidade com a formação de professores de ensino médio ou fundamental, ou em projetos interdisciplinares envolvendo educação, saúde e meio ambiente, por exemplo. O desafio é contaminar o meio universitário com a "ecologia do saberes" que, prevê Boaventura, sofrerá muita resistência no interior da universidade, pois consiste na promoção da convivência, do diálogo entre diferentes modos de conhecimento, dentre os quais o conhecimento é um e não o conhecimento. Trata da valorização de conhecimentos científicos e não científicos cuja "partilha por pesquisadores, estudantes e grupos de cidadãos possibilitam a criação de comunidades epistêmicas mais amplas" (SANTOS, 2008).

\section{CONCLUSÃO}

No âmbito universitário, as metodologias participativas sofreram algum tipo de discriminação e nem sempre foram apoiadas por órgãos de fomento. No entanto, nos últimos dez anos, é incontestável que ganharam espaço em várias universidades, principalmente as do setor público, como também em certas universidades privadas confessionais ou comunitárias. Apesar de ter contribuído para realizar trabalhos de conclusão de curso de graduação, dissertações e teses na 
pós-graduação, pode-se considerar que a metodologia participativa conheceu seu maior crescimento nas atividades de Extensão Universitária, que constitui um espaço suficientemente livre para a realização de projetos participativos em diferentes áreas e com diversas escalas (grupal, institucional, local, regional). Esse fato foi amplamente discutido por ocasião dos SEMPE - Seminários de Metodologia para Projetos de Extensão - organizados desde 1996, em várias universidades do Brasil. Hoje, o evento faz parte das atividades do Fórum de Pró-Reitores de Extensão das Universidades Públicas Brasileiras. O VIII SEMPE, a se realizar em breve, conta entre as comunicações principais com atividades que versam sobre a relação entre a extensão, o ensino e a pesquisa. Contudo, os títulos dos trabalhos selecionados não das pistas de práticas ou estudosarticuladores dos três eixos da atividade universitária.

A construção de sociedades e comunidades sustentáveis, fundada numa "ecologia dos saberes", demanda da universidade uma atuação integradora de suas funções, de seu corpo acadêmico, dos atores sociais, em favor de uma pesquisa-ação a serviço do conjunto da sociedade que articula ensino, pesquisa e extensão.

A pesquisa-ação não oferece um "receituário" pronto. Seu desafio consiste em uma constante renovação teórica e prática, com base no trabalho de pesquisadores, docentes, estudantes, extensionistas e de atores e públicos externos interessados em mudanças e melhorias. Por meio da pesquisa-ação, abre-se espaço para que os diversos profissionais e outros implicados possam interagir de modo interdisciplinar, com pluralidade de perspectivas, de procedimentos investigativos e de planejamento de ações. Ao contrário de certos autores que tendem a reduzir a pesquisa-ação a um único modo de ver centrado no ator, ou a um procedimento padronizado e sem flexibilidade, propomos uma ampla abertura com participação, colaboração ou cooperação (os três termos não são sinônimos e têm graus de profundidade variáveis).

O principal objetivo consiste em aliar produção científica, saberes populares e ações e soluções adequadas ao contexto social, cultural e natural, úteis aos atores e 
conduzidas com ética. A pesquisa-ação não é um método pronto para qualquer uso, em qualquer condição. Sempre está em construção, tanto no nível dos fundamentos, quanto no dos procedimentos. E a contribuição desta proposta à universidade no século XXI coloca uma agenda de tópicos a serem trabalhados:

a) Definir as condições institucionais que permitem o uso da pesquisa-ação, com aspectos de participação, colaboração e/ou cooperação, orientados por valores democráticos, sem correr o risco de desvios de funções ou de manipulação política.

b) Ampliar o papel da pesquisa-ação em contexto universitário, com maior interação entre pesquisa, ensino e extensão e com envolvimento de participantes ou parceiros internos e externos, dentro de projetos ou programas interdisciplinares integrados.

c) Incentivar a metodologia de pesquisa-ação em áreas de interfaces - saúdetrabalho - tecnologia - ecologia - informação - arquitetura - etc.

d) Adequar os princípios de ética de pesquisa com seres humanos (existentes nas áreas de saúde, educação e meio ambiente) aos dispositivos e procedimentos da pesquisa-ação participativa, em particular, no que diz respeito à obtenção de resultados, à responsabilidade nas ações ou decisões, à autoria ou coautoria nas publicações.

e) A pesquisa-ação requer a participação das partes interessadas, sem a qual a proposta perde sua substância e vira procedimento convencional. Obter maior interesse e implicação por parte dos atores constitui um objetivo importante, especialmente em uma época em que há excesso de propaganda e consultas vazias ao público.

f) Capacitar professores, pesquisadores, extensionistas e demais participantes em metodologia participativa e pesquisa-ação, incluindo na programação, além dos procedimentos específicos aos projetos participativos, vários métodos e técnicas de pesquisa qualitativa para dados verbais e visuais, com auxílio de recursos informatizados.

g) Produzir e publicar maior quantidade de conhecimentos baseados na pesquisa-ação em diversos canais, inclusive em veículos digitais e 
audiovisuais. Para os docentes e pesquisadores, é desejável que obtenham maior reconhecimento acadêmico através de publicações em periódicos indexados em diferentes áreas de ciências sociais, educação, administração, etc.

Esta agenda poderá servir de base para futuros trabalhos e discussões tornando a pesquisa-ação mais atualizada, mais bem conhecida e mais atuante na universidade do século XXI.

\section{REFERÊNCIAS}

DIEGUES, Antonio Carlos S. Desenvolvimento Sustentável ou Sociedades Sustentáveis: da crítica dos modelos aos novos paradigmas. São Paulo em Perspectiva, 6(1-2): 22-29, janeiro/junho, 1992.

DIEGUES, Antonio Carlos. Sociedades e Comunidades Sustentáveis. São Paulo. 2003. Disponível em:

http://nupaub.fflch.usp.br/sites/nupaub.fflch.usp.br/files/color/comsust.pdf

DINIZ-PEREIRA, Júlio Emílio; ZEICHNER, Kenneth M. (org.) A pesquisa na formação e no trabalho docente. 2.ed. Belo Horizonte: Autêntica, 2011.

EL ANDALOUSSI, Khalid. Pesquisas-ações. Ciência, Desenvolvimento, Democracia. São Carlos: EdUFSCar, 2004.

ELLIOTT, John. La investigación-acción en educación. Madri: Morata, 1990.

ELLIOTT, John. El cambio educativo desde la investigación-acción. Trad. Pablo Manzano. Madri: Morata, 1993.

EVANS, Roger; RUSSEL, Peter. O Empresário Criativo. São Paulo: Editora Cultrix. 1989.

FREIRE, Paulo. Educação e mudança. Rio de Janeiro: Paz e Terra. 1981.

FREIRE, Paulo. Extensão ou Comunicação? São Paulo: Paz e Terra. 2011.

GARCÍA, Rolando. Interdisciplinariedad y sistemas complejos. In: LEFF, Enrique (Comp.). Ciencias sociales y formación ambiental. Barcelona: Gedisa, 1994. p. 85124.

GERGEN, Kenneth G. Le constructionisme social. Une introduction. Lonay; Paris: Delachaux \& Niestlé, 2001. (Original em inglês: Thousand Oaks, Sage, 1999). 
GOULART, Sueli; VIEIRA, Marcelo M. F. Desenvolvimento, poder local e estrutura simbólico-normativa das universidades. In: Organizações, cultura e desenvolvimento local: a agenda de pesquisa do Observatório da Realidade Organizacional. Recife: EDUFEPE. 2003.

ÍNIIGUEZ, Lupicinio. Construcionismo social. In: MARTINS, João Batista (org.) Temas em Análise Institucional e em Construtivismo Social. São Carlos: Rima; Curitiba: Fundação Araucária, 2002, p. 97-156.

KEMMIS, Stephen; WILKINSON, Mervyn. A pesquisa-ação participativa e o estudo da prática. In: DINIZ-PEREIRA, Júlio Emílio; ZEICHNER, Kenneth M. (org.) $A$ pesquisa na formação e no trabalho docente. 2.ed. Belo Horizonte: Autêntica, 2011, p.39-59.

MORIN, André. Pesquisa-ação integral e sistêmica. Rio de Janeiro: DP\&A, 2004.

MORIN, Edgar. Introdução ao Pensamento Complexo. 4a .ed. Porto Alegre: Sulina, 2011.

PINTO, João Bosco. A pesquisa-ação como prática social. Revista Contexto e Educação, Universidade de ljuí, RS, v.1, n.2, abr. /jun. 1986 p. 27-46. In. DUQUEARRAZOLA, Laura; THIOLLENT, Michel. (textos selecionados e apresentados por). João Bosco Guedes Pinto: Metodologia, Teoria do Conhecimento e Pesquisa-Ação. Rio de Janeiro: PDF, 2013.

SANTOS, Boaventura de Sousa; ALMEIDA FILHO, Naomar. A Universidade no Século XXI: Para uma Universidade Nova. Coimbra: pdf. 2008.

SOUSA SANTOS, Boaventura de. A Universidade do século XXI. Para uma reforma democrática e emancipatória da Universidade. 3.ed. São Paulo: Cortez, 2010.

THIOLLENT, Michel. Metodologia da Pesquisa-Ação. São Paulo: Cortez. 1985.

THIOLLENT, Michel. Pesquisa-Ação e Pesquisa Participante: Uma Visão De Conjunto. Relatório final de atividades do projeto "apoio metodológico a projetos de pesquisa e extensão universitária baseados em metodologias participativas e de pesquisa-ação". Rio de Janeiro: FAPERJ, 2010.

THIOLLENT, Michel. Action research and participatory research. An overview. International Journal of Action Research, v. 7, n. 2, p.160-174, 2011. Disponível em: http://wp.ufpel.edu.br/consagro/files/2011/11/THIOLLENT-Michel-Action-Researchand-Participatory.pdf

VIEIRA, Eurípedes Falcão \& VIEIRA, Marcelo Milano Falcão. Universidades Federais - Uma Experiência Dimensionada no Tempo-Espaço da Atualidade. Gestão.Org, v. 2, n. 2, mai./ago. 2004. www.gestaoorg.dca.ufpe.br 